\title{
ACTION OF ORAL AND PARENTERAL BETHANECHOL ON DECOMPENSATED BLADDER
}

\author{
ANANIAS C. DIOKNO, M.D. \\ JACK LAPIDES, M.D.
}

From the Department of Surgery, Section of Urology,

University of Michigan Medical Center, Ann Arbor, Michigan

\begin{abstract}
A double blind balanced Latin-square study was conducted on 20 adult patients with decompensated bladders to determine the relative effectiveness of oral and parenteral bethanechol chloride (Urecholine) on the stretch response of bladder muscle. Detrusor reaction was measured by modified cystometry. Five mg. of subcutaneous bethanechol chloride produced a significant increase in intravesical pressure which was more rapid in onset, of larger magnitude, and of shorter duration than oral doses of 100 and $200 \mathrm{mg}$.
\end{abstract}

Because of the relative paucity of data in the literature documenting the efficacy of oral bethanechol (Urecholine) in stimulating the urinary bladder ${ }^{1}$ and since the cholinergic agent is employed so widely, it was deemed of interest to conduct a double blind randomized study on a group of patients with partial or complete urinary retention.

\section{Material and Methods}

Twenty patients ranging in age from eighteen to eighty-five years and including 11 females, were selected as subjects. Eight individuals were able to urinate but with postvoiding residual urine volumes greater than $100 \mathrm{ml}$. The remaining 12 people required catheter drainage because of complete retention; 8 males were on cystostomy tubes, 1 on intermittent catheterization, and 4 females on inlying urethral catheter.

The patients were subjected to a series of modified cystometric studies, each having one set of cystometrographs daily for five days. Prior to the cystometric run the patient received one of five combinations of oral and subcutaneous doses of bethanechol which were unknown at the time of administration (Table I). The $5 \mathrm{mg}$. and the placebo subcutaneous doses were contained in similar 1-ml. ampules while the placebo, $50 \mathrm{mg}$., $100 \mathrm{mg}$., and $200 \mathrm{mg}$, oral doses were incorporated in identical appearing tablets.
TABLE I. Combinations of oral and subcutaneous doses

\begin{tabular}{|c|c|c|}
\hline \multirow{2}{*}{$\begin{array}{c}\text { Treatment } \\
\text { Day }\end{array}$} & \multicolumn{2}{|c|}{-Route- } \\
\hline & Oral & Subcutaneous \\
\hline 1 & Placebo & $\begin{array}{l}\text { Urecholine } \\
5 \mathrm{mg} \text {. }\end{array}$ \\
\hline 2 & Urecholine $50 \mathrm{mg}$. & Placebo \\
\hline 3 & Urecholine $100 \mathrm{mg}$. & Placebo \\
\hline 4 & Urecholine $200 \mathrm{mg}$. & Placebo \\
\hline 5 & Placebo & Placebo \\
\hline
\end{tabular}

The Merrill gas cystometer was utilized in the study. The bladder was filled with air at a rate of $100 \mathrm{ml}$. per minute. A continuous recording of intravesical pressure was obtained to $100 \mathrm{ml}$. of bladder capacity. The test dose by the oral and subcutaneous route was then administered and the cystometric study repeated at ten, twenty, thirty, forty-five, and one hundred twenty minutes. The temperature, pulse rate, respiratory rate, blood pressure, skin color, moisture, pupil diameter, peristaltic activity, and bowel movements were recorded before and throughout the period of study. The anticholinergic agent, atropine sulfate, was available at all times for any side effects.

The intravesical pressure observed at $100-\mathrm{ml}$. bladder volume during the control cystometrograph prior to administration of the test medication was considered as the base line value. The 
response of the detrusor to the various drug combinations was determined from the intravesical pressure at $100-\mathrm{ml}$. volume noted at ten, twenty, thirty, forty-five, ninety, and one hundred twenty minutes after administration of a particular medication. The mean of all the intravesical pressures at the various time intervals for each test done was computed, tabulated, and plotted in a graph.

\section{Results and Comment}

Although 20 patients were started on the study, only 17 were subjected to the entire five sets of unknown combinations of bethanechol and placebo. Three patients could not tolerate the oral 200-mg. dose of bethanechol, and thus their sets of cystometrographs were incomplete.

The mean intravesical pressure changes occurring after administration of the various doses of bethanechol are depicted in Figure 1. It will be observed that the 5-mg. subcutaneous dose stimulated a more rapid response of the detrusor than did the oral doses of 50, 100, and $200 \mathrm{mg}$. Parenteral bethanechol produced a significant intravesical pressure rise within ten minutes after injection, the peak effect at thirty minutes, and complete subsidence within one hundred twenty minutes.

Ingested bethanechol failed to produce a perceptible response of the detrusor muscle at the 50-mg. dose level but did elicit significant increases in intravesical pressure with greater drug quantities. When bethanechol is taken per os, it will be observed in Figure 1 that the cholinergic agent is slower to act than the subcutaneous dose but maintains its effectiveness for a longer period of time than the parenteral medication.

A mild degree of sweating was observed in 9 patients receiving $200 \mathrm{mg}$., 1 patient with 100 mg., and 5 patients administered $5 \mathrm{mg}$. subcutaneously. Profuse sweating was noted in 1 patient who received $200 \mathrm{mg}$. and 1 patient who received $5 \mathrm{mg}$. subcutaneously. Diarrhea developed in 1 patient after the 200-mg. session was completed. With the same dose, 2 patients felt cold and chilly, and in 1 patient bradycardia and hypotension developed.

Four patients received atropine after 200 mg. of bethanechol orally. Two patients received the anticholinergic drug after the fortyfive-minute cystometry, while 2 patients were given atropine at the conclusion of the session.

The present balanced Latin-square, controlled dose response study to determine the

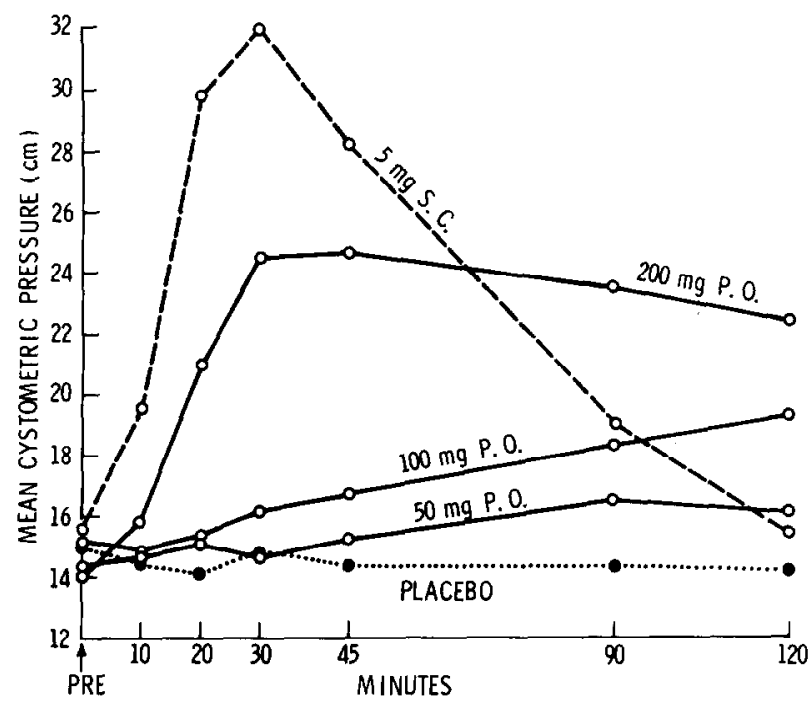

Figure 1. Composite graph of mean intravesical pressure at 100-ml. volume before and at various times after bethanechol administration.

oral dose of bethanechol that is clinically equivalent to $5 \mathrm{mg}$. of the drug administered subcutaneously, is entirely in accord with a similar investigation reported previously. ${ }^{1} \mathrm{Be}-$ cause of the prolonged action of ingested bethanechol and the possibility of cumulative effect with frequent repeated oral administration, it would be safest to use oral bethanechol in doses less than $100 \mathrm{mg}$. given every four to six hours. If one desires to use larger doses, the patient should be hospitalized where strict surveillance can be obtained.

Our observations reaffirm the fact that the detrusor stimulation by parenteral bethanechol is dissipated completely within two hours after injection; and thus subcutaneous injections can be repeated at three-hour intervals without concern about cumulative responses.

We should like to emphasize that this study evaluated the localized stretch response of bladder muscle to oral and parenteral bethanechol administration and not the ability of the bladder to empty itself. Although $50 \mathrm{mg}$. of oral bethanechol caused little change in intravesical pressurc, this dosage has been found to be very effective clinically in the rehabilitation of decompensated bladders. ${ }^{2,3}$

Ann Arbor, Michigan 48109 (DR. DIOKNO)

\section{References}

1. Lapides J, Friend CR, Ajemian E, and Sonda LP: Comparison of action of oral parenteral bethanechol chloride upon the urinary bladder, Invest. Urol. 1: 94 (1963).

2. Lapides J: Urecholine regimen for rehabilitating the the atonic bladder, J. Urol. 91: 658 (1964).

3. IDEM: Neurogenic bladder: principles of treatment, Urol. Clin. North Am. 1: 81 (1974). 